\title{
Effect of Sinter-cake Load Reduction by Magnetic Force on Iron Ore Sintering
}

\author{
Tadahiro INAZUMI, Masami FUJIMOTO, Shuichi SATO ${ }^{1)}$ and Keiji SATO') \\ Process Technology Research Laboratories, Nippon Steel Corporation, Shintomi, Futtsu, Chiba-ken, 293 Japan. \\ 1) Plant Engineering \& Technology Center, Nippon Steel Corporation, Shintomi, Futtsu, Chiba-ken, 293 Japan.
}

(Received on October 31, 1994; accepted in final form on December 16, 1994)

\begin{abstract}
The permeability of the combustion-melting zone in the sintering bed of the Dwight-Lloyd process, which affects process efficiency in terms of productivity and product yield as well as quality control, was found to be dependent largely on the sinter cake load upon the combustion-melting zone during sintering. In order to control and reduce the sinter cake load, the magnetically-levitated sintering method was devised. As a result of sintering pot tests, the sintering time was shortended by a maximum of $30 \%$ without a decrease in product yield and coke combustion efficiency was improved despite an acceleration of sintering speed. In addition, the reduction degradation index, RDI, and reducibility, JIS-RI, were improved. The size distribution of product sinter tends to be sharp. Improvement in permeability were proportional to the degree of load reduction. CT analyses of sinter cake samples showed that the load on the combustion-melting zone during sintering accelerates ordinarily the plugging of stem pores with melt and disturbs gas flow through the sintering bed in the middle and bottom layer. The permeability improvements resulting from applying the magnetic levitation are attributed to the formation of a homogeneous network with a pore size appropriate for gas flow as well as increase in porosity of stem pores by about $\mathbf{8 \%}$.
\end{abstract}

KEY WORDS: sinter cake load; permeability; productivity; product yield; quality of sinter; pore network; pore structure; magnetic levitation; magnetism of iron ore sinter.

\section{Introduction}

The air flow rate distribution along the sintering strand of the Dwight-Lloyd, DL, process under constant suction pressure is known to be uneven, depending on gas flow resistance in the sintering bed. The main cause of the resistance increase at the ignition furnace has been ascribed to the moisture condensation from the upper layer of the sintering bed to the lower layers composed of raw mixture. ${ }^{1,2)}$ The combustion-melting zone is enlarged with a progress of sintering and increases in gas flow resistance in the bed, which in turn also retards the sintering speed. ${ }^{2)}$ As the cause of the resistance increase, gas volume expansion by heating in the combustionmelting zone and plugging of gas channels by increase of melt volume have been considered. ${ }^{2)}$ The former is fundamentally clear and it is possible to assume the extent of the resistance theoretically, but as for the latter, details have not been known because of the difficulty of analyzing combustion-melting zone structure.

Thus the authors have directed their attention to the effect of the sinter cake load upon the combustionmelting zone on the permeability and studied how the sinter cake load would affect permeability through the structural changes of stem pores formed during the sintering reactions with the use of CT (computerized tomograph) analytical technique. ${ }^{3)}$ For controlling and reducing sinter cake load, a magnetic levitation method was devised. The results of pot test sintering with the use of magnetic force showed that the reduction of sinter cake load sharply improved permeability of the combustion-melting zone.

\section{Experimental Method}

\subsection{Apparatus of Sinter Cake Load Reduction}

To reduce the sinter cake load, an upward force corresponding to the resultant downward force on the sinter cake by the weight of sinter cake and by blower suction pressure act in the sintering bed. In principle, the following three methods of reducing the sinter cake load can be considered.

(1) Levitating sinter cake by magnetic force

(2) Lifting sinter cake by rods with connection to sinter cake

(3) Statically supporting the sinter cake by steel stands ${ }^{4)}$

These methods are classified into two kinds: method (1) is a remote action, while methods (2) and (3) are those of direct action and include mechanical lifting rods or supporting stands in the bed. In order to analyze the effect of sinter cake load upon the combustion-melting zone on sintering reaction without thermal and gas flow disturbance by inserting an additional apparatus in the 


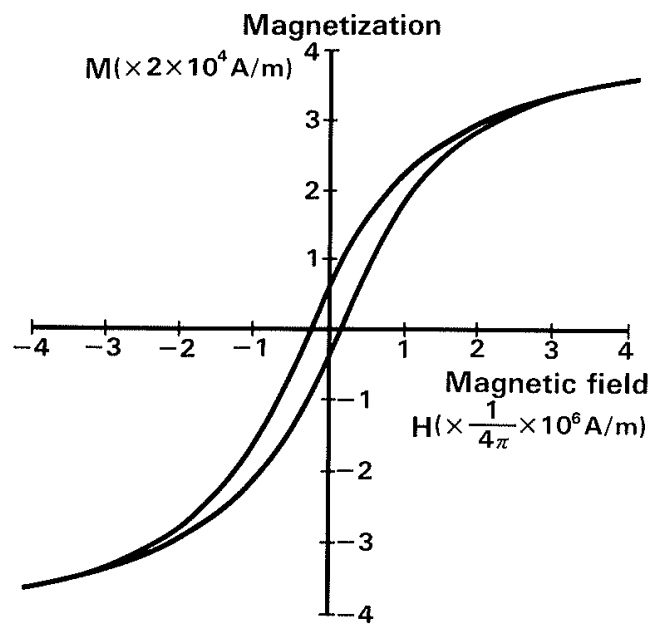

Fig. 1. Magnetization curve of sinter ore.

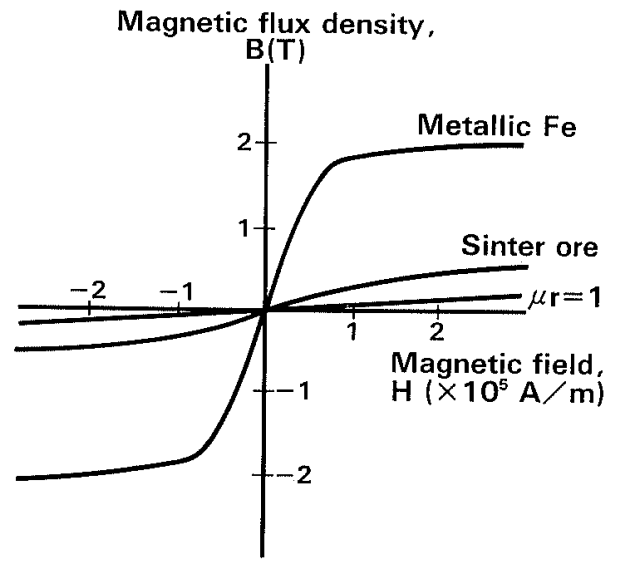

Fig. 2. $B-H$ curve of sinter ore, comparing magnetism of metallic iron.

bed, magnetic levitation sintering is most appropriate. In addition, the magnetic levitation method with electric control system has superior controllability of load.

Thus here the magnetic levitation method has been an object of development for the experiment apparatus.

\subsection{Magnetically-levitated Sintering Method}

\subsubsection{Magnetism of Sinter Cake}

Figures 1 and $\mathbf{2}$ show the measured magnetic properties of sinter powder by vibrating sample magneto-meter. ${ }^{5)}$

Clear magnetic hysteresis is observed (Fig. 1). The $B-H$ curve slope $\mu_{r}$ or relative magnetic permeability of the sinter itself is small and is saturated as a low magnetic flux density, when compared with that of metallic iron (Fig. 2). However, the value of the relative magnetic permeability 1.2 to 1.8 at a magnetic flux density of $0.2 \mathrm{~T}$ is possible according to the principle that the application of a strong magnetic field to sinter cake surface should create gradient and produce what is called the Maxwell force ${ }^{6)}$ which attracts and levitates the sinter cake (Eq. (1)).

$$
\begin{array}{r}
f_{y}=\left(1-1 / \mu_{r}\right) B_{y}^{2} / 2 \mu_{0}+\mu_{0}\left(\mu_{r}-1\right) H_{x}^{2} / 2 \\
B_{y}=\mu_{0} \mu_{r} H_{x}
\end{array}
$$

where, $f_{y}$ : Maxwell force (N),

$\mu_{0}$ : Magnetic permeability in vacuum (-),

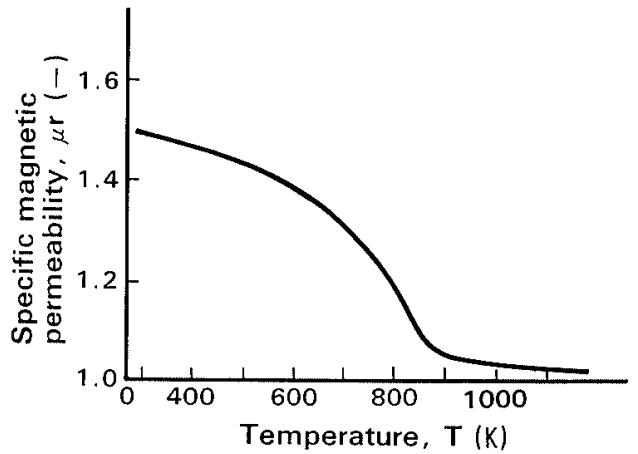

Fig. 3. Temperature dependence of sinter ore magnetism.

$\mu_{r}:$ Specific magnetic permeability of magnetic material (-),

$H_{x}$ : Magnetic flux density vertical to boundary between magnetic material and air $(\mathrm{A} / \mathrm{m})$,

$B_{y}$ : Magnetic field horizontal to boundary between magnetic material and air $(\mathrm{T})$.

Furthermore, the temperature dependence of magnetic property of sinter powder was studied. With increasing temperature, sinter powder gradually decreases its relative magnetic permeability and loses the magnetism when the temperature rises to about $900 \mathrm{~K}$ (Fig. 3). As the DL process is characteristic in that sinter cake in the sintering bed is exposed to cooling air and is not so hot at the top, the magnetic levitation force is considered to be applicable. However, as the upper layer of sinter bed is also exposed to relatively weak heat radiation from the combustion-melting zone of the lower layer, the effect of heat radiation on magnetic force needs to be checked.

For sinter cake, a preliminary magnetic levitation test showed that magnetic levitation force also depends strongly on sinter cake porosity and gaps between sinter cake surface and magnetic pole as well as relative magnetic permeability mentioned above. Magnetism of sinter also is dependent on mineral constitution, especially on magnetite content, however, in this test sintering was carried out with the same raw mixture and under the constant ignition condition, so that the mineral constitution, in turn the magnetism, is considered to be constant.

\subsubsection{Experimental Apparatus of Sintering Pot Test} with Use of Magnetic Levitation Force

Magnetic forces necessary to levitate sinter cake were simulated by FEN calculation system ${ }^{7)}$ on the basis of the findings mentioned above. And an experimental apparatus capable of developing a magnetic levitation force matching the total load of the sinter cake was designed, constructed and equipped with a $300 \mathrm{~mm}$ diameter sintering test pot, as illustrated schematically in Fig. 4.

The experimental apparatus succeeded in magnetically levitating about $100 \mathrm{~kg}$ of sinter cake at room temperature with a magnetic pole flux density of $0.6 \mathrm{~T}$. In addition, reduction of magnetic force by the heat radiation from the combustion-melting zone was checked by the following test. During sintering a magnetic levitation force was abruptly cut and the change of load 


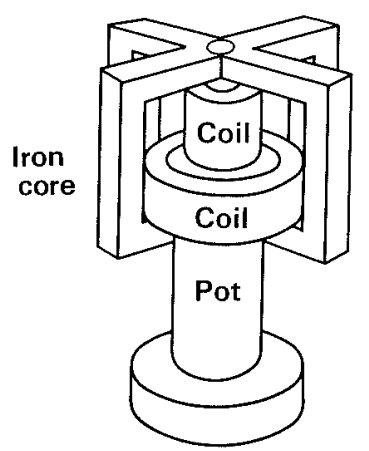

(a) General view

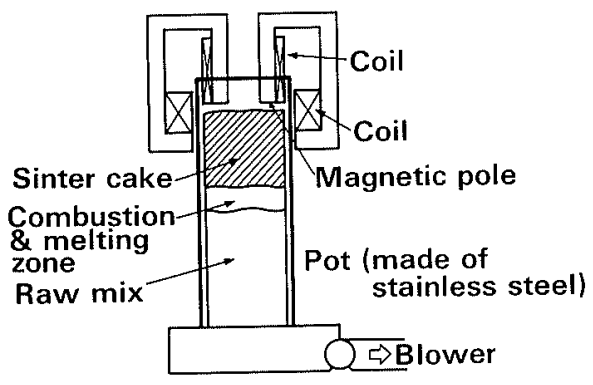

(b) Vertical section
Fig. 4.

Experimental apparatus of sintering by control of sinter cake load with use of magnetic force.

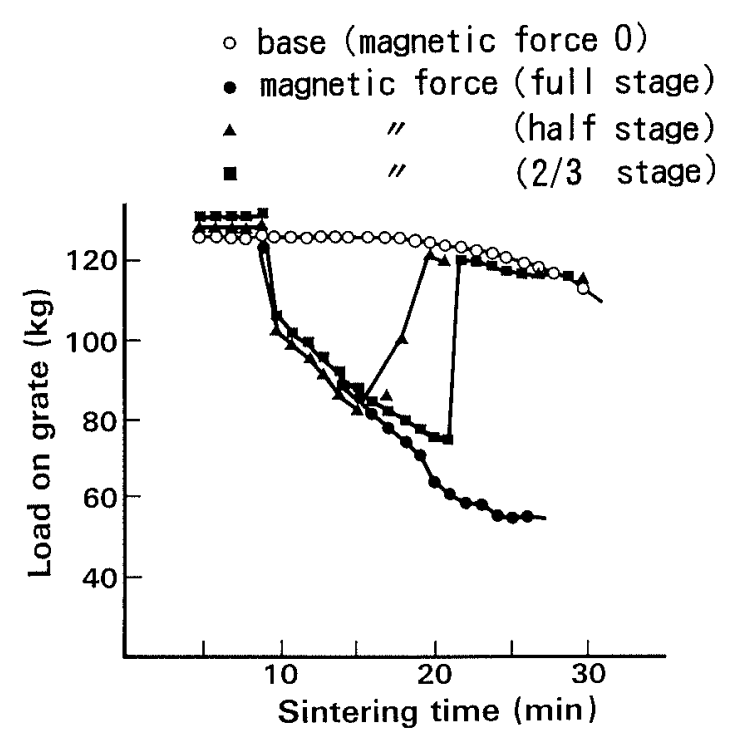

Fig. 5. Change of sinter cake load during sintering with use of magnetic force.

was measured by load cell installed beneath the pot grate. Figure 5 shows the test results. In the case of sintering without magnetic force, slight reduction of the load on the pot grate is observed due to the evapolation of water and combustion of coke only. On the other hand, in the case of magnetic levitation sintering, the load continues to reduce with the volume increase of the levitated sinter cake until the end of sintering. On the half and two thirds stage of sintering when the current of electromagnetic coil is turned off, the load rises abruptly to the base condition. This load reduction test showed that the magnetic levitation apparatus can develop a high enough levitation force and the effect of heat radiation from the combustion-melting zone is negligible in practice (Fig. 5).

\subsection{Experimental Conditions of Magnetically-levitated Sintering}

Sintering pot tests with use of the magnetic levitation apparatus were carried out. A practical raw mixture was used for sintering in a $300 \mathrm{~mm}$ diameter test pot under a constant suction pressure of $9.8 \mathrm{kPa}$. Bed height was set to $600 \mathrm{~mm}$. In addition, to analyze the dependence of bed height on magnetic levitation effect, bet height was changed up to $800 \mathrm{~mm}$. The base condition was the application of no magnetic force. The magnetic force was applied above $10 \mathrm{~min}$ after ignition. The load on
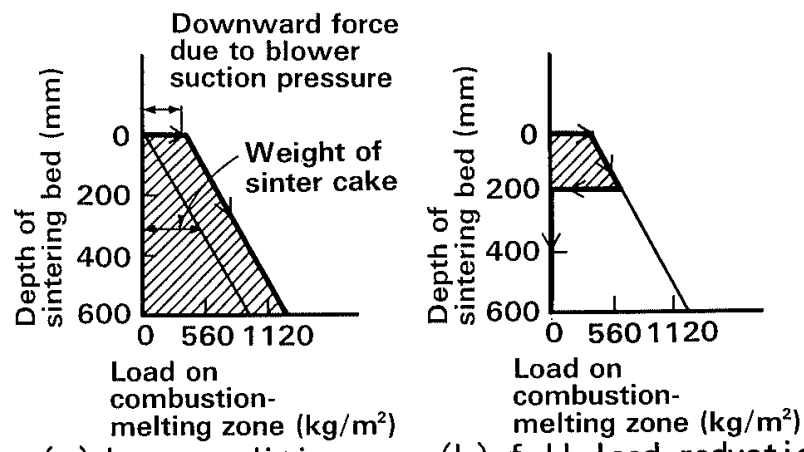

(a) base condition

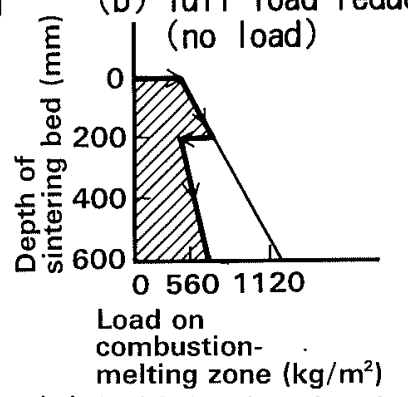

(c) half load reduction

Fig. 6. Experimental conditions of magnetically-levitated sintering tests.

the combustion-melting zone in the middle and bottom layers of the sinter bed was set at zero or reduced by half (Figs. 6(b) and 6(c)) by changing the current supplied to electromagnetic coils according to the bed depth. The load on the combustion-melting zone was calculated on the assumption that the weight of sinter cake is proportional to sintering time and the downward force by blower suction pressure is constant ${ }^{8)}$ (Fig. 6(a)). Duplicated pot tests for each experimental condition were conducted. One test was for evaluation of sintering time, product yield and quality, while the other was for analysis of sinter cake structure with the use of CT analytical technique previously reported ${ }^{3)}$ by one of the authors.

\section{Experimental Results}

\subsection{Pot Test Results of Magnetically-levitated Sintering}

The sintering time was shortened by a maximum of $30 \%$ when sinter cake load on the combustion-melting zone during sintering was set at zero (Fig. 7). Furthermore the product yield did not drop despite the acceleration of sintering speed. Eventually, productivity was 
(a)

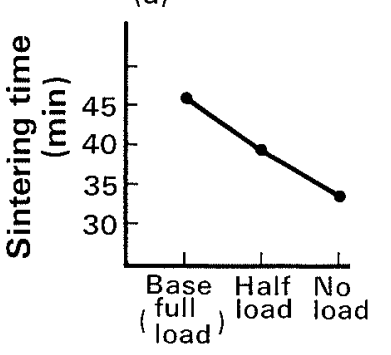

Experimental condition (b)

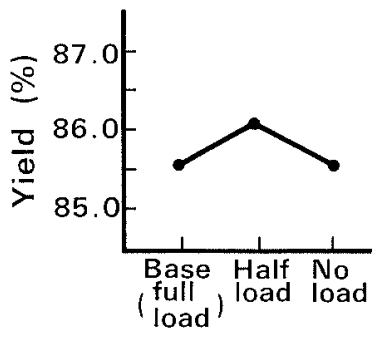

Experimental condition

Fig. 7. Effect of sinter cake load reduction by magnetic force on sintering time and product yield.

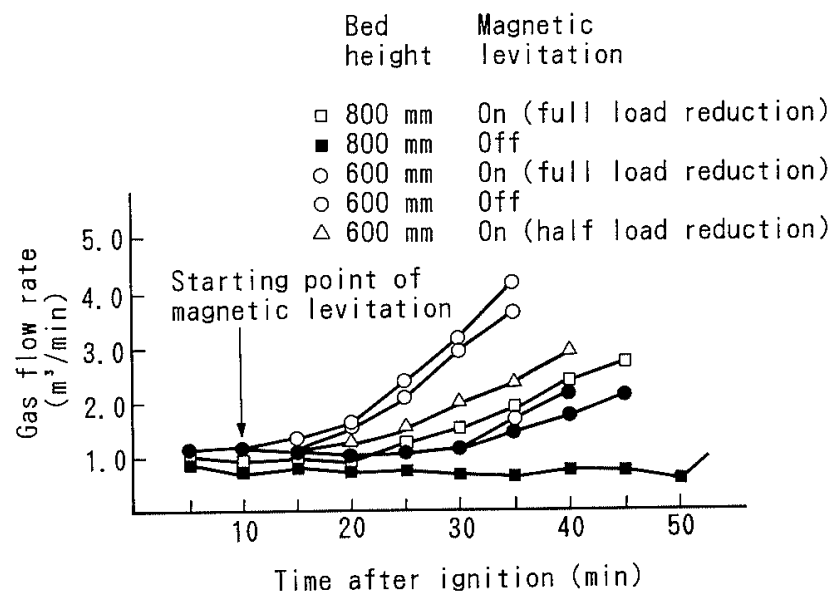

Fig. 8. Effect of magnetic levitation on flow rate of exhaust gas.

Table 1. Effect of magnetic levitation sintering on $\mathrm{CO}, \mathrm{CO}_{2}$ content of exhaust gas.

\begin{tabular}{cccccc}
\hline \multirow{2}{*}{$\begin{array}{c}\text { Time after } \\
\text { ignition } \\
(\mathrm{min})\end{array}$} & \multicolumn{2}{c}{$\begin{array}{c}\text { Base condition } \\
\text { (Experiment No. 1) }\end{array}$} & & \multicolumn{2}{c}{$\begin{array}{c}\text { Magnetic levitation } \\
\text { sintering(Experiment No. 2) }\end{array}$} \\
\cline { 2 - 3 } \cline { 5 - 6 } \cline { 5 - 6 } & $\mathrm{CO}(\%)$ & $\mathrm{CO}_{2}(\%)$ & & $\mathrm{CO}(\%)$ & $\mathrm{CO}_{2}(\%)$ \\
\hline 5 & 1.30 & 11.08 & & 1.32 & 11.52 \\
10 & 1.58 & 12.64 & & 1.58 & 13.18 \\
15 & 1.64 & 12.68 & & 1.58 & 12.74 \\
20 & 1.76 & 12.66 & & 1.59 & 12.60 \\
25 & 1.66 & 12.64 & & 1.59 & 12.12 \\
30 & 2.01 & 12.70 & & 0.52 & 5.64 \\
35 & 0.82 & 5.20 & & 0.15 & 0.74 \\
40 & 0.29 & 0.52 & & & \\
45 & 0.24 & 0.24 & & \\
\hline
\end{tabular}

improved by up to a maximum of $30 \%$. The sintering time reduction is ascribed to the increase of gas flow rate. The gas flow rate increased from the starting point of magnetic levitation, and was especially conspicuous in the latter half stage of sintering (Fig. 8). On the other hand, under the base condition the gas velocity is low in the middle stage despite the enlargement of sintered layer with low resistance of gas flow. The reason is ascribed to the increase of the resistance in the combustion-melting zone. The sharp rise of gas velocity at the end under the base condition is due to the diminishment of the combustion-melting zone by burning out of coke.

In addition, despite the significantly increased rate of

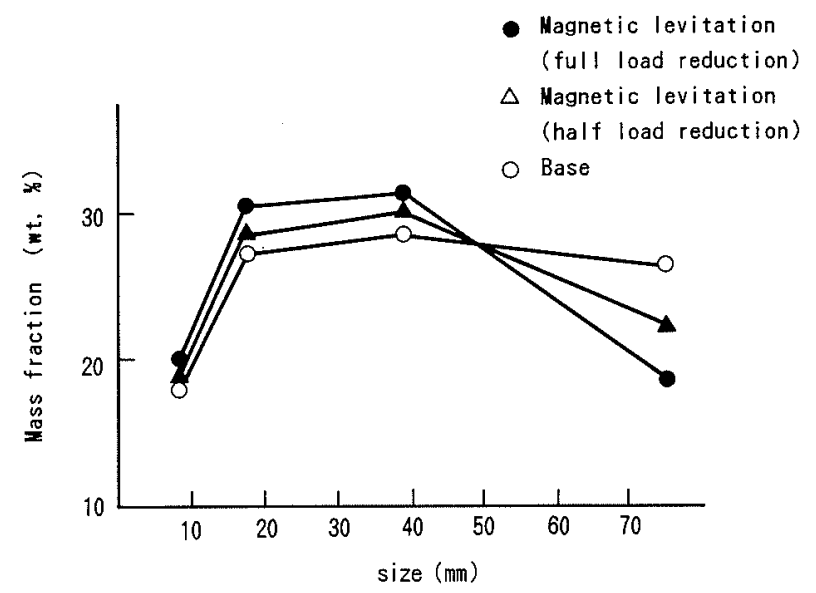

Fig. 9. Change of size distribution of product sinter by magnetic levitation sitering.

Table 2. Experimental conditions and results of pot sinter test with and without magnetic force. (full: full load reduction, half: half load reduction)

\begin{tabular}{|c|c|c|c|c|c|}
\hline \multirow[b]{2}{*}{$\begin{array}{c}\text { Experiment } \\
\text { No. }\end{array}$} & \multicolumn{2}{|c|}{ Experiment conditions } & \multicolumn{3}{|c|}{ Experiment results } \\
\hline & $\begin{array}{l}\text { Magnetic } \\
\text { force }\end{array}$ & $\begin{array}{l}\text { Bed depth } \\
(\mathrm{mm})\end{array}$ & $\begin{array}{l}\text { Produc- } \\
\text { tivity } \\
\left(\mathrm{t} / \mathrm{d} / \mathrm{m}^{2}\right)\end{array}$ & $\begin{array}{l}\text { Yield } \\
(\%)\end{array}$ & $\begin{array}{c}\text { Sintering } \\
\text { time } \\
\text { (min) }\end{array}$ \\
\hline No. 1 & off (base) & 600 & 26.05 & 85.57 & 46.1 \\
\hline No. 2 & on (full) & 600 & 35.68 & 85.10 & 33.9 \\
\hline No. 3 & on (half) & 600 & 31.28 & 86.09 & 39.3 \\
\hline No. $1 \mathrm{~A}$ & off (base) & 600 & 26.79 & 85.46 & 43.6 \\
\hline No. $2 \mathrm{~A}$ & on (full) & 600 & 35.66 & 85.56 & 33.0 \\
\hline No. 4 & off (base) & 800 & 24.66 & 89.82 & 69.5 \\
\hline No. 5 & on (full) & 800 & 33.12 & 87.99 & 50.7 \\
\hline
\end{tabular}

coke combustion resulting from the sintering time reduction by magnetic levitation sintering, the carbon monoxide utilization, $\eta$ co, of the waste gas exhibited some improvement (Table 1). As for quality of sinter, reducibility was improved, the reduction degradation index (RDI) was improved, and the particle size distribution of product sinter was sharpened (Fig. 9).

When the sinter cake load was halved, the reduction in the sintering time was approximately half the value of that under no sinter cake load, indicating that the effect is proportional to the extent of sinter cake load reduction (Fig. 7).

The same order of improvement of productivity was found in the case of high bed height of $800 \mathrm{~mm}$ (Table 2). The gas flow rate increased by magnetic levitation compared to the base condition (Fig. 8). As for product yield, the increase of bed height to $800 \mathrm{~mm}$ improved product yield both in magnetic levitation and base conditions. Eventually the increase in bed height using magnetic levitation apparatus resulted in improving both productivity and product yield.

\section{Structural Changes of Sinter Cake by Magnetically- levitated Sintering}

\subsection{General Change of Sinter Cake Structure}

The structure of sinter cake obtained by magnetic 


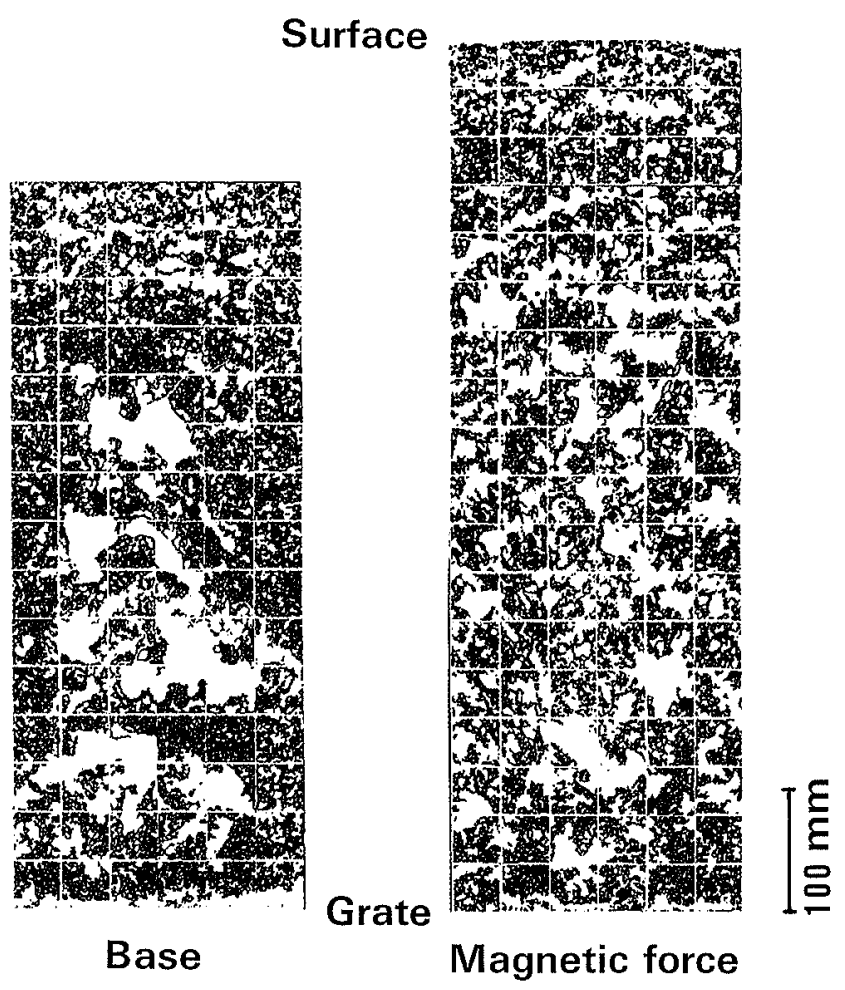

Fig. 10. CT figures of vertical section of sinter cake with and without use of magnetic force and conventional one.

Table 3. Porosity of sinter cake by pore type with and without magnetic force.

\begin{tabular}{lccc}
\hline & $\begin{array}{c}\text { Total } \\
\text { porosity (\%) }\end{array}$ & $\begin{array}{c}\text { Porosity of } \\
\text { stem pores (\%) }\end{array}$ & $\begin{array}{c}\text { Porosity of } \\
\text { closed pores (\%) }\end{array}$ \\
\hline Base condition & 56.2 & 49.1 & 7.1 \\
Magnetic levitation & 61.4 & 55.9 & 5.4 \\
\hline
\end{tabular}

levitation sintering has the same characteristic both in the samples of 600 and $800 \mathrm{~mm}$ bed height. As for the structure under the base condition, the characteristic both in the samples of 600 and $800 \mathrm{~mm}$ is also same, but the structure of the sample of $800 \mathrm{~mm}$ is more heterogenous than that of $600 \mathrm{~mm}$. Therefore, in order to analyze the structural difference more clearly the analytical results of the samples with $800 \mathrm{~mm}$ bed height have been shown in Fig. 10.

From the height difference of sinter cake in the photograph the magnetic levitation was observed to have reduced the sintering shrinkage by about $80 \mathrm{~mm}$. The increase of volume by magnetic levitation sintering is attributed to the increase of porosity (Table 1).

In addition, general view of the structure shows that the magnetic levitation sintering made a sinter cake structure homogeneous in the middle and bottom layers (Fig. 10).

\subsection{Structural Change of Permeable Pore}

\subsubsection{Pore Type and Pore Size}

In order to clarify the details of the change in the permeable pore structure, the change in the ratio of closed pores to stem pores by magnetic levitation sintering was measured. According to the authors' previous stereographic studies $^{9,10)}$ of pores, pores of under $5 \mathrm{~mm}$ are
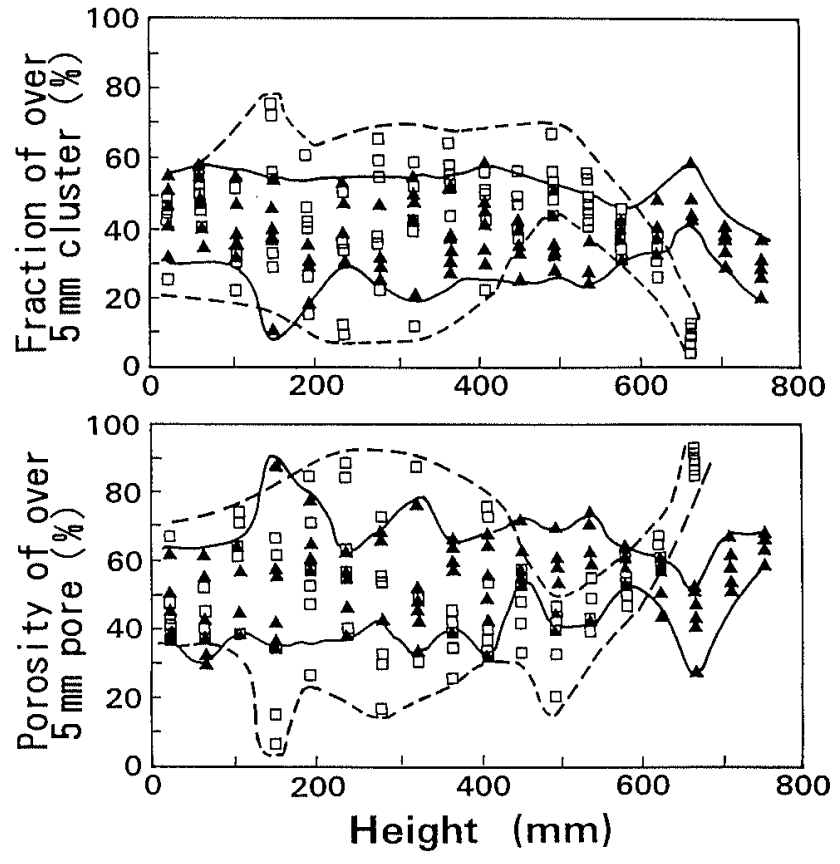

\section{$\square$ : base $\quad \Delta$ : magnetic force}

Fig. 11. Change of large size of cluster and pore by control of sinter cake load with use of magnetic force.

closed pores and pores of over $5 \mathrm{~mm}$ are open or stem pores. Changes in total porosity and the porosity of closed pores and open pores are shown in Table 3. By magnetic levitation sintering, the total porosity increased by $8 \%$ with especially the ratio of stem pores (which effectively promote gas flow) to closed pores increasing. The porosity of the closed pores did not change, being kept at the same level as that of the base condition. As for pore size, under the base condition, both large and small pores coexist and location of the large pores are segregated. It is considered that segregated large pores disturb smooth and homogeneous gas flow through the sintering bed. By magnetic levitation sintering, the variation in the ratio of $+5 \mathrm{~mm}$ pores became smaller than that of the base condition, so that the size of the pores was homogenized (Fig. 11). Each data item in this figure shows the average measurement values of $40 \mathrm{~mm}$ cubic sinter cake samples, ${ }^{9)}$ which are indicated by sectioned lines in the figure.

\subsubsection{Change of Pore Network Structure}

The pore network is composed of various types of pores $^{11)}$ : stem pores, pores with node-like channels and discontinuous pores having the end. At this time, with the use of the topological method the network structure of connected pores was characterized as follows:

(1) To visualize the linkage state of pores more clearly, skeletons which represent the central lines of pores used to be drawn. ${ }^{12)}$ For skeletoning of pores, at first the pores were divided into Voronoi triangles (The left side figures in Figs. 12 and 13) and then the straight lines were drawn by connecting the circumcenters of the three adjacent triangles. ${ }^{13)}$ The lines are not shown in the figure.

(2) In order to find out effective channels for permeation, after discontinuous lines having the end were 

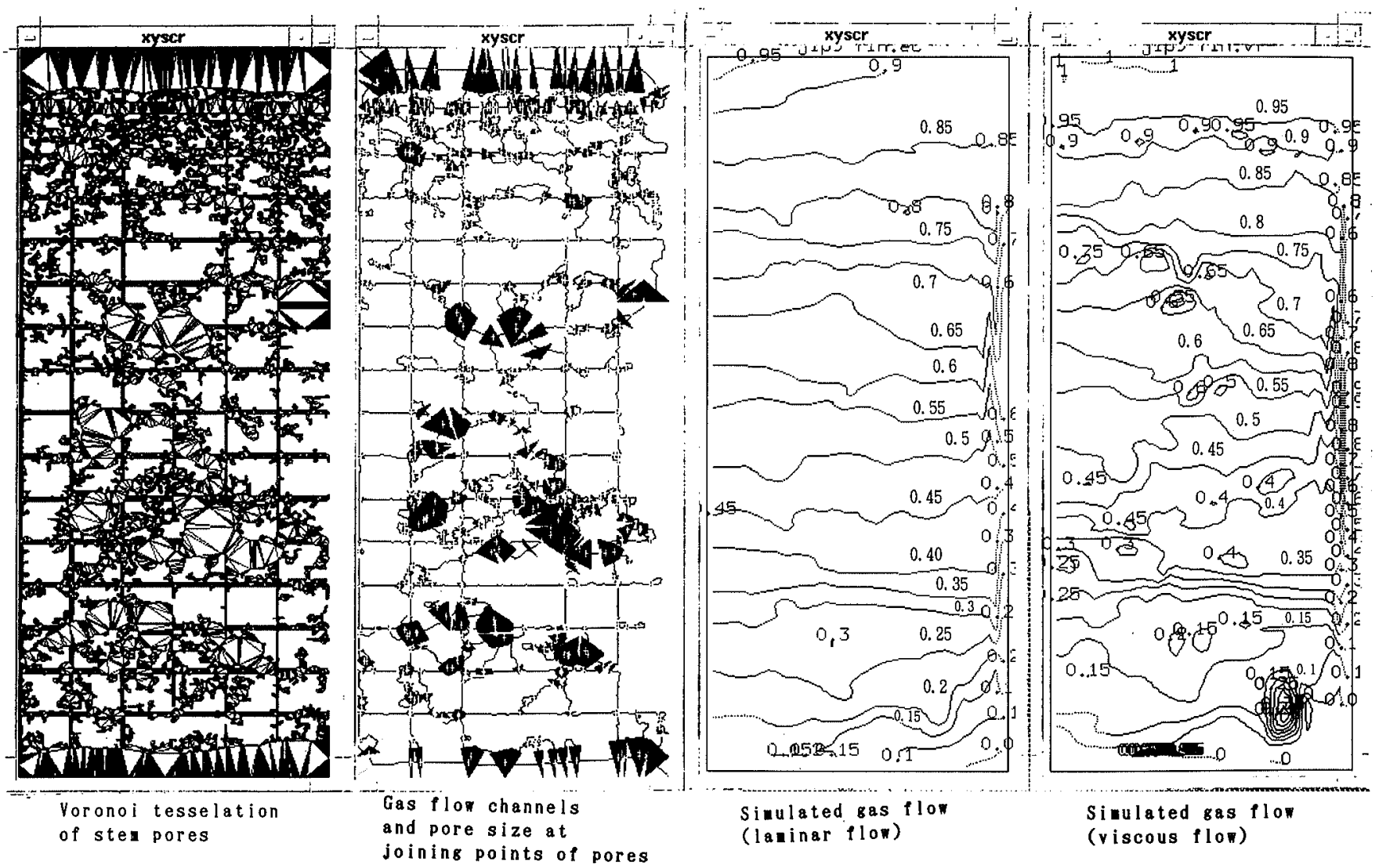

Fig. 12. Analytical result of pore network in conventional sinter cake. (Numerical figures indicate the ratio of pressure to total pressure)

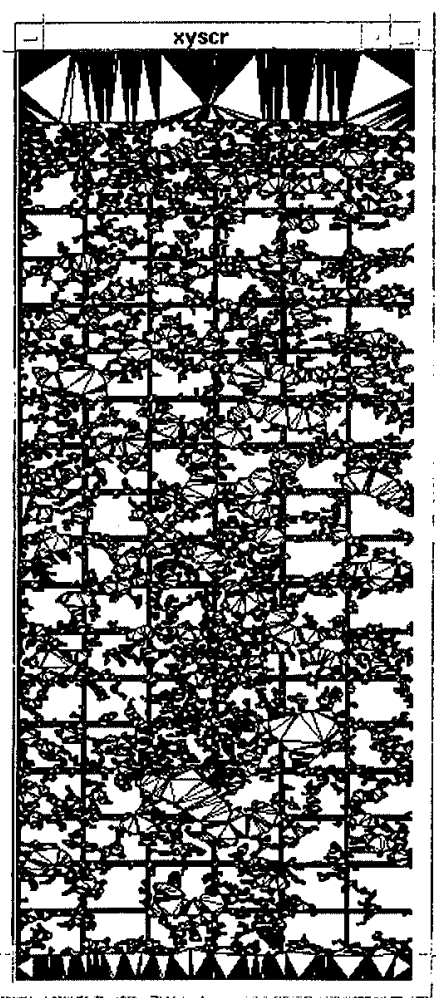

Voronoi tesselation

of stew pores

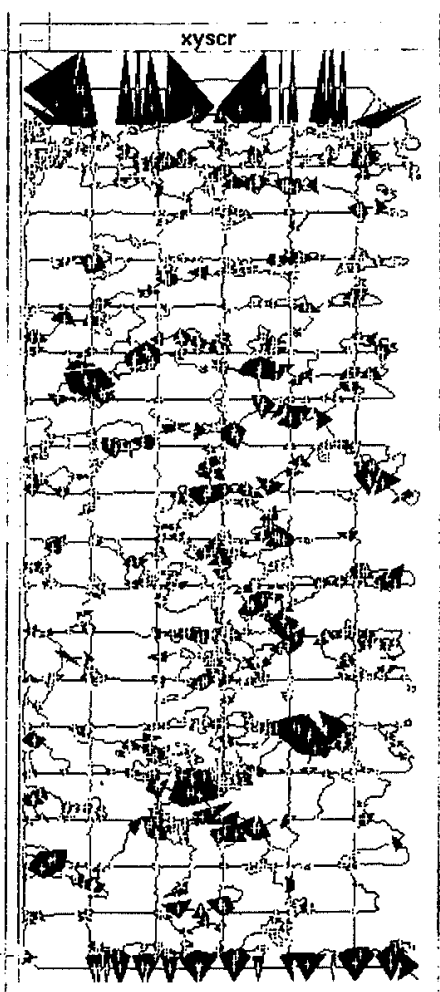

Gas flow channels

and pore size at

joining points of pores

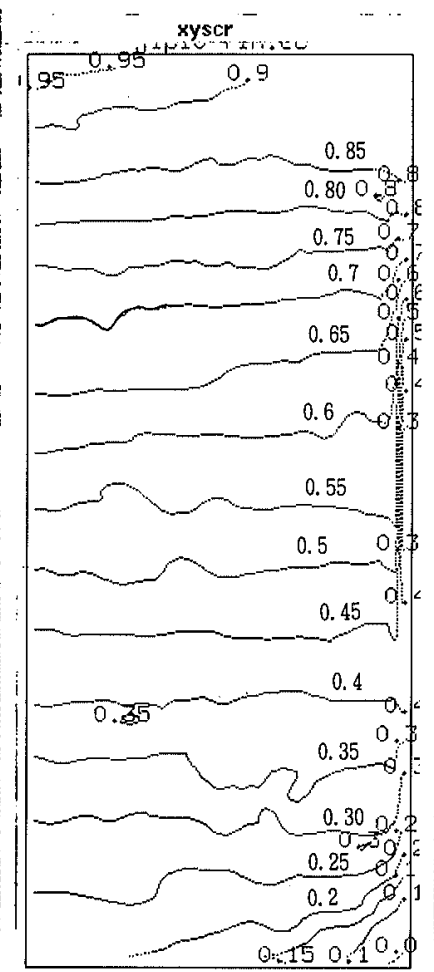

Sinulated gas flow

(laainar flow)

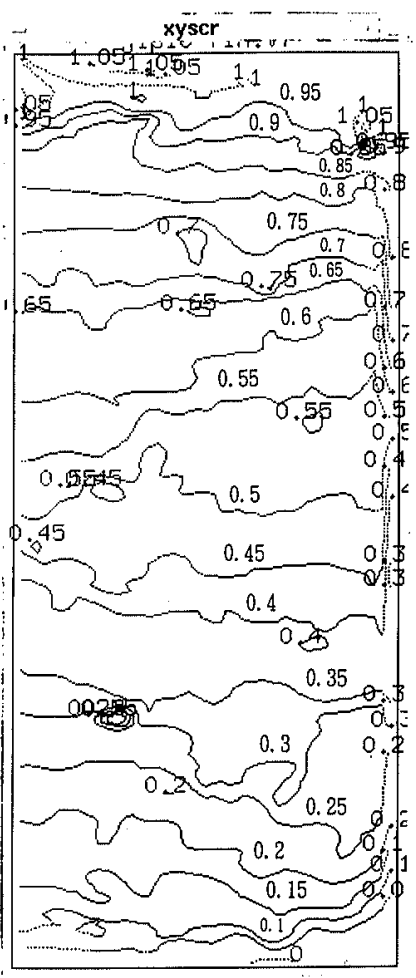

Sinulated gas flon

(viscous flon)

Fig. 13. Analytical result of pore network in magnetic levitation. (Numerical figures indicate the ratio of pressure to total pressure) 
cut off from the skeletons, effective channels for gas flow were obtained (the second figure from the left side in each Figs. 12 and 13). In the case of magnetic levitation sintering, the effective network of pores having a small amount of discontinuous pores was formed.

(3) Size of air pocket also affects air flow. The polyhedral in the figure shows such size of pores at the joining points of pores. Many large polyhedrals, in the case of the base condition, were diminished in size and dispersed uniformly as small pores throughout the sinter cake by the magnetic levitation sintering.

\subsubsection{Simulation of Gas Flow through Sinter Cake}

Simulation of gas flow through sinter cake was carried out using Kirchhock Eq. (3) ${ }^{12,13,3)}$ and branch (unit element of pore network) parameters such as branch length and branch width. The calculations were carried out on the assumption of both viscous flow and laminar flow.

$$
Q=-a b c \Delta P
$$

$Q$ : Flow rate $\left(\mathrm{m}^{3} / \mathrm{sec}\right), \Delta P$ : Suction pressure $(\mathrm{Pa})$. $a=1 / \mu$ (in case of viscous flow),

$a=\sigma$ (in case of laminar flow)

$\mu$ : Viscosity (-) $\sigma$ : Resistance of flow (-)

$b=1 / L^{2}$ (in case of viscous flow),

$b=L$ (in case of laminar flow)

$L:$ Branch length (m)

$c=W^{3} / L$ (in case of viscous flow),

$c=W / L$ (in case of laminar flow)

$W$ : Branch width (m)

The calculated results are shown by isobars in the right side figures in Figs. 12 and 13. Comparing the structural differences in sinter cake along the bed height, the differences under the middle layers are conspicuous between the samples of magnetic levitation sintering and base condition sintering. The calculated gas flow under the base condition showed irregular flow both in the directions of bed height and latitude, and it became homogeneous due to magnetic levitation sintering. The reduction of sinter cake load is considered to have prevented the squeezing of pores by the load in the combustion-melting zone, resulting in increasing the porosity of stem pores and making a uniform pore network. By these changes in pore structure, rate acceleration and homogenization of heat exchange and coke combustion in the combustion-melting zone are considered to have been promoted.

\subsection{Change of Solid Portion Structure}

In the CT figure, sinter cake looks like a connected mass formed by the coalescence of fine particles, and a group of clusters (small aggregate unit) having various size. Under the base condition, large and compact clusters were observed in the middle and bottom layers, looking like rock, having poor permeability (Fig. 10). The high compactness in the clusters is considered to disturb gas flow and to cause large and locally segregated pores to be formed. Also, under or near such compact clusters, unsintered portions with small size of clusters were observed. Coexistence of compacted and unsintered portion shows that uneven sintering occurred in the
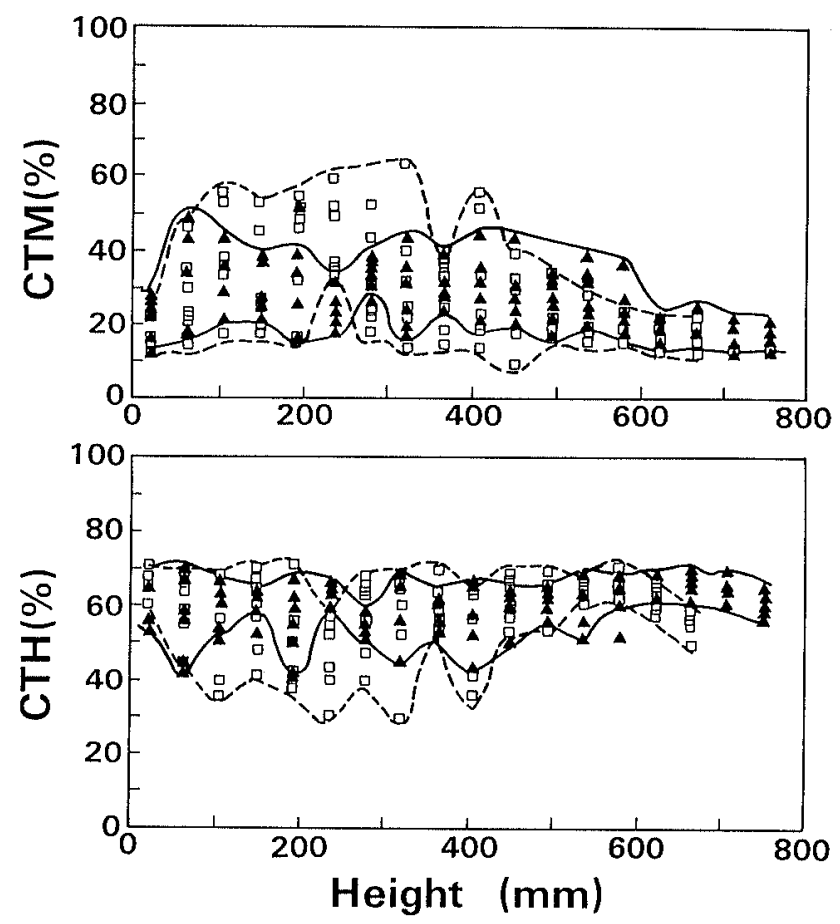

\section{$\square$ : base $\Delta$ : magnetic force}

Fig. 14. Change of CTM (\%) and CTH (\%) of sinter cake by control of sinter cake load with use of magnetic force.

layers with high compactness.

The difference between the compactness in the solid portion of the sinter cake with and without magnetic levitation was measured quantitatively by CT. As compactness of the solid portion is proportional to the apparent density of the solid portion, the area percentage of the portion with high density, $\mathrm{CTH},{ }^{9)}$ and that with medium density, CTM, ${ }^{9)}$ were measured (Fig. 14). As a result, it was found that rocky clusters with high density were diminished, and clusters with a medium density were increased by magnetic levitation sintering. As for cluster size, the same tendency as that regarding the change of compactness of solid portion by magnetic levitation sintering was observed. Figure 11 shows that $+5 \mathrm{~mm}$ clusters, that is the clusters with product size, were changed and converged to the average and representative value of that of the base condition. This change is considered to be the reason why the size distribution of product sinter has sharpened.

\subsection{Consideration of the Relationship between Sinter Cake Structure and Sintering Performance}

The improvement of sintering performance by magnetic levitation sintering is considered to be dependent on the structural changes in the sinter cake. As the sinter cake is obtained by a consolidation of the combustion-melting zone, changes in sinter cake structure are considered to also reflect the structural changes in the combustion-melting zone.

High productivity due to high permeability and homogeneous gas flow is considered to be brought about by the formation of a homogeneous pore network with an appropriate pore size for gas flow as well as by an 
increase in porosity. Despite acceleration of sintering speed, there was no drop in product yield. The high coke combustion efficiency and improvements in sinter qualities are considered to be attributed to the homogenization of sintering by a dispersed gas flow. That is, the ratio of the over-melted portion to the adequatelysintered portions is considered to have decreased.

Ramberg and Eketorp ${ }^{2)}$ pointed out that the pressure drop per unit length of the wet raw mix zone increases in proportional to the level of the combustion-melting zone. The raw mix with condensed water is considered to become compact and dense under the sinter cake load, resulting in the formation of a high-resistance layer for gas flow. Besides the improvement in the sinter cake structure, the effect of the compaction reduction in the raw mix layer on sintering will be included in the results of the present test. This effect will be studied in details in the future.

On the other hand as for the upper layer, a difference between the sinter cake structure with the base condition and that with magnetic levitation sintering could not be found. This result is natural because magnetic levitation started when sintering occurred at the middle layer. It is considered that in the upper layer, magnetic levitation is not necessary and rather compressive force is necessary from the viewpoint of the sinter cake structure, because the compactness in the upper layer is far less and the cluster size is smaller than the average and representative level of normal sinter.

\section{Conclusions}

(1) Permeability in the lower layer of the sintering bed affecting productivity, product yield and quality of sinter was found to be dependent largely on the sinter cake load on the combustion-melting zone during sintering.

(2) Controlling and reducing the sinter cake load at zero by magnetically-levitated sintering methods were effective for shortening sintering time by a maximum of $30 \%$ without a drop in product yield. In addition, RDI and JIS-RI improved. Size distribution of product sinter was sharpened.

(3) These improvements by applying magnetic levitation sintering were attributed to the formation of a homogeneous pore network with appopriate pore size for gas flow as well as an increase of porosity of stem pores by about $8 \%$.

\section{REFERENCES}

1) R. Wild and K. G. Dixton: Agglomeration, ed. by W. A. Knepper, Interscience, New York, (1962), 565.

2) B. Ramberg and S. Eketorp: Jernkont. Ann., 148 (1964), 897.

3) T. Inazumi, S. Kasama, K. Ito, T. Nakano and H. Mizushima: Trans. JIM, 31 (1992), 440

4) M. Fujimoto and T. Inazumi: CAMP-ISIJ, 4 (1991), 1128.

5) S. Chikazumi: Physics of Magnetism, John Wiley \& Sons, New York, (1964), 120.

6) Y. Miyazoe: Denjikigaku II, Asakurashoten, Tokyo, (1987), 111.

7) T. Nakata and N. Takahashi: FEN for Electiric Engineering II, Morikita Shuppan, Tokyo, (1991), 25.

8) T. Inazumi, M. Fujimoto, S. Amano, S. Matunaga, T. Nakayasu, S. Sato, K. Sato, and Y. Sensui: The first ICSTI, 1994, Sendai, Japan, ISIJ, Tokyo, (1994), 487.

9) T. Inazumi, T. Kasama, K. Sato, M. Sasaki and T. Tanaka: Proc. 5th Int. Conf. Agglomeration, Sep. (1989), Brighton, UK, 559.

10) S. Kasama, T. Inazumi and T. Nakayasu: Tetsu-to-Hagané, 78 (1992), 1069

11) F. A. Dullien: Porous Media, Academic Press, New York, (1979), 90.

12) S. Kirkpatrick: Rev. Mod. Phys., 43 (1973), 574.

13) T. Nakano and N. Fujii: Geoinformaties, 2 (1991), 45, 275. 